\title{
Marine epibiosis. III. Possible antifouling defense adaptations in Polysyncraton lacazei (Giard) (Didemnidae, Ascidiacea)
}

\author{
Martin Wahl ${ }^{1}$ and Bernard Banaigs ${ }^{2}$ \\ ${ }^{1}$ Zoologisches Institut, Universität Kiel, Kiel, FRG $;{ }^{2}$ Laboratoire Chimie Marine (GERAP), Université de \\ Perpignan, Perpignan, France
}

(Received 2 April 1990; revision received 10 September 1990; accepted 22 September 1990)

\begin{abstract}
Polysyncraton lacazei (Giard), a colonial tunicate of the western Mediterranean, seems to be well-protected against epibiosis. Out of several thousand potential colonizers estimated, only one kamptozoan species, Loxocalyx sp., is found with some regularity $(\leq 21 \%)$ on the colonial surface. The results in this paper suggest the existence of overlapping mechanical, chemical and extrinsic adaptations with a good antifouling potential.
\end{abstract}

Key words: Antifouling defense; Ascidian; Epibiosis; Polysyncraton lacazei

\section{INTRODUCTION}

Fouling, i.e., the colonization of living or nonliving surfaces by sessile microorganisms, plants or animals is an omnipresent phenomenon in the marine environment. The intensity of fouling on a given surface depends on at least three major parameters: (i) Local fouling pressure, which in itself is a product of the local pool of potential colonizers and the 'biological activity' of local waters (temperature, nutrients, illumination, etc.). (ii) Exposure time of the surface considered, which may be determined by an organism's longevity, the mean frequency of physical disturbance of mineral substrata, etc. (iii) Physicochemical properties of a nonliving surface (roughness, wettability, color, toxicity, etc.) or an organism's antifouling defenses in a wide sense (see below). Thus. there seems to be a general tendency for nondefended substrata in a tropical habitat to become fouled more rapidly and/or more diversely than the same object in arctic waters or one inherently unsuitable to fouling (toxic, defended).

As for any other substratum, sessile marine organisms that are fairly long-lived and grow exposed (i.e., nonburrowing) either become colonized eventually or have to protect their body surface against epibionts.

In this paper, we will examine the case of the colonial ascidian Polysyncraton lacazei (Giard) (Didemnidae). As shown previously (Wahl \& Lafargue, 1990), this species

Correspondence address: M. Wahl, Zoologisches Institut, Universität Kiel, 2300 Kiel, FRG. 
depends on a 'clean' colony surface for efficient filtration. In fact, with the exception of one kamptozoan species, Loxocalyx sp., as a more or less regular epibiont, the surface of this ascidian is perfectly clean, even sterile. This is a remarkable performance in view of this species' longevity (2-4 yr) and the heavy local fouling pressure (probably $>2000$ colonizer species, only $3 \mathrm{wk}$ from exposure of test plates to settlement of metazoan larvae; Wahl, 1987). These observations suggest that $P$. lacazei possesses one or more rather efficient antifouling defense adaptations. Possible defense mechanisms (reviewed in Wahl, 1989), that might be used by P. lacazei, are. (i) Mechanical defense: (a) Intense superficial mucus production and/or continuous mucus ablation; (b) Periodical cuticula/epidermis sloughing; (c) Migrating surface-bound mucus film. (ii) Physical defense: (a) Surface wettability within the "biocompatible zone" (20-30 $\mathrm{dyn} \cdot \mathrm{cm}^{-1}$ ). (iii) Chemica! defense: (a) Extreme basic or acidic surface pH values; (b) Surfacebound or exuded toxic secondary metabolites.

In the following, we will try to find out which (if any) of these antifouling adaptations could explain the near-total absence of epibionts on P. lacazei.

\section{MATERIALS}

P. lacaze $i$ is a colonial ascidian belonging to the Didemnidae. The zooids are tiny $(1-3 \mathrm{~mm})$ and linked to the colonia! surface by their branchial siphon openings (diameter $0.25 \mathrm{~mm}$ ). The atrial siphons open into a common intracolonial canal system which communicates with the exterior by few larger exhalant apertures (diameter $\approx 1 \mathrm{~mm}$ ). Colonies are encrusting, flat $(5-10 \mathrm{~nm})$ and may reach diameters of 10-20 (rarely 30 ) $\mathrm{cm}$ in the study area.

This investigation was carried out at Laboratoire Arago at Banyuls-sur-Mer on the French Mediterranean coast $\left(42^{\circ} 29^{\prime} \mathrm{N}, 3^{\circ} 8^{\prime} \mathrm{E}\right)$. Here, $P$. lacazei mostly grows on rocky substrata between 2 and $30 \mathrm{~m}$ depth. Colonies were collected by scuba diving and either fixed immediately in ethanol (chemical analysis) or transferred to the laboratory's flow-through aquarium for biological investigation.

\section{METHODS}

MECHANICAL DEFENSE

Migrating mucous surface film?

Freshly collected colonies (diameter $5 \mathrm{~cm}$ ) were placed on a horizontal glass plate in al-1 flow-through aquarium $\left(11 \cdot \mathrm{h}^{-1}, 15^{\circ} \mathrm{C}\right)$. Care was taken that no lateral currents occurred in the neighborhood of the colony. After 1-2 h, differently sized particles of grounded bivalve shell were strewn on the colony surface. The smallest particles were a fine powder (diameter $\approx 50 \mu \mathrm{m}$ ) whereas the largest ones measured $\approx 1 \mathrm{~mm}$ in 
diameter. Distribution and "motion" of the particles were monitored photographically $\left(1\right.$ picture $\left.\cdot 2 \min ^{-1}\right)$ over $48 \mathrm{~h}$.

\section{Continuous mucus secretion?}

Colonies were transferred to a covered chamber with water-saturated air. Under these conditions, they survive without harm for several hours. With the help of a soft hairbrush, pigment particles of neutral red where distributed on the colony surface. After 0.5-1 h, the particles had sunken into the cuticular surface layer and the colonies were returned to a flow-through tank $\left(50 \mathrm{l}, 101 \cdot \mathrm{h}^{-1}, 15^{\circ} \mathrm{C}\right)$ where they took up normal filtering activity within a few minutes. Macrophoto sequences $\left(1\right.$ picture $\cdot$ day $\left.^{-1}\right)$ over 22 days documented the evolution of the stain particles within the colonial surface.

\section{Sloughing?}

Occurrence of sloughing events was monitored in situ and in vitro by (i) underwater macrophotography during a 4-yr in situ survey of several P. lacazei colonies and (ii) stereomicroscope examination of 15-20 freshly collected colonies weekly over $1 \mathrm{yr}$ (n=910).

\section{PHYSICAL DEFENSE}

Measuring surface tension or wettability of mineral, metallic or polymerous surfaces, which may be adequately prepared in various ways (e.g., Neumann \& Good, 1979), is much easier and uncomparably more precise than trying to get even a rough idea of these physical properties on a living organism's surface. Our objective was simply to find out whether the surface wettability of $P$. lacazei colonies ranges near or within the biocompatible zone $\left(20-30 \mathrm{dyn} \cdot \mathrm{cm}^{-1}\right)$ or, on the contrary, well outside it.

To this aim, we slightly modified the "adhering bubble method" and the "sessile drop method" (Neumann \& Good, 1979). As wettability was to be established for a living, healthy and unstressed miarine organism, several prerequisites had to be respected. (i) The animal must constantly be kept immersed. (ii) The liquid bulk phase had to be $35 \%$ artificial seawater. (iii) Bulk phase and animal had to be maintained at $\angle 8^{\circ} \mathrm{C}$ to induce a moderate anaesthesia of the $\left(25^{\circ} \mathrm{C}\right.$-adapted) test organism, thus, minimizing filtration activity and colony contractions. (iv) The measuring fluids had to be perfectly nontoxic and chemically inert with regard to the coiony surface. (v) The organism's surface must be clean and fairly smooth. Stereomicroscope examination of each test specimen showed that healthy, epibiont-free and rinsed $P$. lacazei colonies did meet this last requirement to an acceptable degree.

The three phases finally used were: P. lacazei colonies (solid), artificial seawater $\left(35^{\circ}, 8^{\circ} \mathrm{C}, \mathrm{pH} 8 \pm 0.2\right)$ (Fluid 1, bulk phase) and air or silicon oil (Rhodorsil 641V200, $\gamma<20 \mathrm{dyn} \cdot \mathrm{cm}^{-1}$, Fluid 2). The experimental setup is illustrated in Fig. 1. Preliminary tests on solid phases with known surface tensions [glass, polymethylmethacrylate 
(PMMA), Parafilm] showed that the influence of those properties of the bulk phase that differed from standard parameters (salinity, temperature), largely compensated one another: $35 \%$ as compared with $0 \%$ lowered the apparent surface tension by 5 (PMMA) to 2 (Parafilm) dyn $\cdot \mathrm{cm}^{-1}$ at $21^{\circ} \mathrm{C}$, while the lower test temperature $\left(8^{\circ} \mathrm{C}\right.$ as compared with $21^{\circ} \mathrm{C}$ ) raised the apparent surface tension by 3 and $2 \mathrm{dyn} \cdot \mathrm{cm}^{-1}$, respectively. Corsequently, these artefacts will not seriously affect our results.

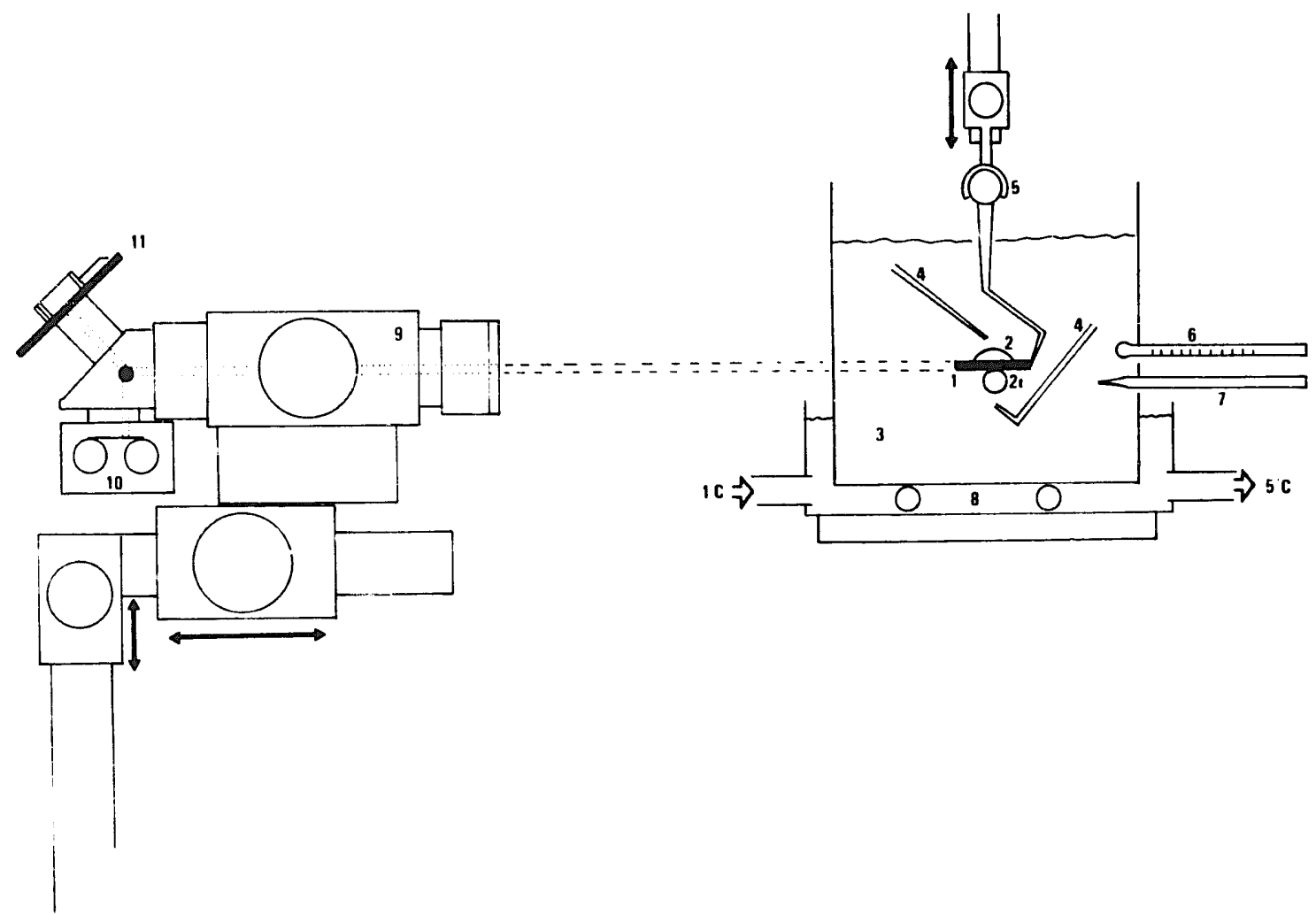

Fig. 1. Experimental setup for surface tension evaluation. 1, solid phase (e.g., P. lacazei colony); 2a, liquidmeasuring phase (silicone oil drop); $2 \mathrm{~b}$, gaseous-measuring phase (air bubble); 3 , liquid bulk phase (35\% seawater, $8^{\circ} \mathrm{C}$, pH $8 \pm 0.2$ ); 4 , micropipette; 5 , ball-and-socket-joint; 6 , thermometer; 7 , pH meter; 8 , refrigeration; 9 , stereomicroscope; 10 , photographic unit; 11 , goniometer.

Freshly collected colonies were selected for smooth epibiont-free surfaces, attached to glass cover slides and left to adapt in a flow-through tank $\left(25^{\circ} \mathrm{C}\right)$ for 1 day. Then, they were rinsed gently with sterile seawater $\left(25^{\circ} \mathrm{C}\right)$, transferred directly to the cooled test tank and oriented horizontally. Contact-angle measurements were conducted according to Neumann \& Good (1979). For each drop or bubble, we noted the mean of right and left contact angle. 10 bubbles (air) or drops (silicon oil) on each of 10 colonies were measured photographically and by a goniometer device mounted on a Wild stereomicroscope. 


\section{CHEMICAL DEFENSE}

\section{Surface $p H$}

Many ascidians display extremely low $\mathrm{pH}$ values in certain sulfuric acid-containing vacuoles of the subsurface tunic (Stoecker, 1978, 1980). Usually, these acids are readily liberated on slight mechanical stimulus (but certainly not by the settlement of microepibionts or sedimenting detritus particles). Thus, it is important in this context to establish the acidity of the unmolested, intact colony surface. Several methods were employed to illustrate (and eliminate) the influence of unsuitable techniques on the results.

Contact methods. (i) Indicator paper (Acilit, pH 0-6; Merck, Darmstadt, FRG) was pressed slightly, moderately and firmly onto the still wet colony surface.

(ii) The aqueous surface film of still-wet colonies was sucked off with finely pointed Whatman 1 filter paper. Then, a tiny drop of one of a series of indicator fluids with different overlapping $\mathrm{pH}$ ranges (thymol blue, bromophenol blue, methyl red, bromocresol purple, bromothymol blue, phenol red) was added to the wetted tip of the filter paper strip.

Contact-free methods. (i) For this experiment, we used colonies that had completely overgrown gorgonian branches. Thus, their entire outer surface constituted "upper" surface with siphon openings. The attachment side was hidden within the colony. Specimens were suspended in the air above a glass beaker. During $70 \mathrm{~min}$, drops of artificial seawater ( $\mathrm{pH} 7.54,10$ drops $\cdot \mathrm{min}^{-1}$ ) falling from a burette $2 \mathrm{~cm}$ above the colony gently washed over its outer surface and finally were collected in the beaker where the $\mathrm{pH}$ change was monitored.

(ii) Freshly collected colonies were put in a glass dish with artificial seawater. Under the stereomicroscope, drops of different indicator fluids (see above) were released onto the surface of the colony (technique slightly modified after Parry, 1984). Color changes were noted.

\section{Secondary metabolites}

The chemical extraction and fractionation was accompanied by biological tests (see below). Only biologically active fractions were further treated.

Chemical treatment. P. lacazei $(\approx 300 \mathrm{~g}$ dry wt) collected in April 1986 was stored in ethanol. The alcohol was decanted, the whole animal was ground to a powder with a blender and extracted three times with $50 \% \mathrm{CHCl}_{3}$ in ethanol. After filtration, the original ethanol solution and the $\mathrm{CHCl}_{3}$ /ethanol solutions were combined and the organic solvents were evaporated at $40^{\circ} \mathrm{C}$ under vacuum.

The aqueous residue, diluted with distilled water, was transferred to a separatory 
funnel and was successively partitioned between $n$-hexane $(3 \times 1 \mathrm{l})$-water, diethyl ether $(3 \times 11)$-water, methylene chloride $(3 \times 11)$-water and finally $n$-butanol $(3 \times 11)$-water. Removal of solvant from the $n$-hexane, diethyl ether, methylene chloride and $n$-butanol solutions gave $18.8 \mathrm{~g}$ (HEX), $1.1 \mathrm{~g}(\mathrm{ET}), 1.9 \mathrm{~g}\left(\mathrm{CH}_{2} \mathrm{Cl}_{2}\right)$ and $\approx 20 \mathrm{~g}$ (BUT) extracts, respectively.

Chromatographic procedures (of biologically active fractions): $10 \mathrm{~g}$ of the hexanic extract were loaded onto an open Silicagel column $\left(\mathrm{SiO}_{2}, \mathrm{Merck}, 60-230-\mu \mathrm{m}\right.$ mesh), which was packed in methylene chloride and eluted with a solvent gradient from pure $\mathrm{CH}_{2} \mathrm{Cl}_{2}$ to $10 \%$ of $\mathrm{MeOH}$ in $\mathrm{CH}_{2} \mathrm{Cl}_{2} .19$ secondary fractions of $500 \mathrm{ml}$ were collected (H1-H19), concentrated $\left(40^{\circ} \mathrm{C}\right.$, vacuum) monitored by TLC (thin-layer chromatography) and submitted to biological screening. High-performance liquid chromatography (HPLC) of the main "active" fraction $\mathrm{H} 10$ using $35 \%$ ethyl acetate in isooctane on a R-Sil silica 5 column yielded eight HPLC (tertiary) fractions (H10.1-H10.8). A set of eight pics were indeed detected (differential refractometer) during the HPLC fractionation. Further examination of the spectral features (IR and nuclear magnetic resonance) of the tertiary HPLC fractions showed that $\mathrm{H} 10.1$ and $\mathrm{H} 10.2$ are mixtures of lipids, $\mathrm{H} 10.3$ is a mixture of sterols and $\mathrm{H} 10.4-\mathrm{H} 10.8$ are steroid compounds. $2.5 \mathrm{~g}$ of the butanolic extract, dissolved in distilled water, was centrifuged. The residue (B0) was submitted directly to biological tests and the supernatant was collected, passed through a Sephadex Gi5 column and eluted with $1 \%$ acetic acid in water (column size $1 \times 120 \mathrm{~cm}$ ). Secondary fractions B1-B9 were collected.

Biological screening. P. lacazei extracts were tested for biological activity using target organisms that represent the major fouling groups with the exception of macroalgae (Wahl, 1989).

Antibacterial: Benthic bacteria were isolated from the sediment surface in the immediate vicinity of the extracted $P$. lacazei population. One epibiotic bacterium was obtained from the colony surface of Cystodytes dellechiajei (Della Valle), another local colonial ascidian. Lastly, we used a marine Pseudomonas strain from the Laboratoire Arago collection. All strains were identified as far as possible by the API plate test (API system, Montalieu Vercieu, France):

Benthic bacteria: Strain IG1 (whitish colonies; big, rod-shaped, motile forms; Gramnegative; API code 212410650): Pseudomonas sp. Strain IG2 (whitish colonies; small, rod-shaped, motile forms; Gram-negative; API code 00000(440): unidentifiable. Strain IG3: (yellowish colonies; coccoid, motile forms; Gram-positive; API code 000000453): Micrococcus sp.

Epibiotic strain: Strain CYS (red, hemispherical colonies; aggregating, rod-shaped, motile forms; Gram-positive; API code 000000471): Corynebacterium sp.

Laboratory strain: Strain PSEUD (whitish colonies; small, rod-shaped, motile forms; Gram-negative; API code 000000450): Pseudomonas sp.

Culture medium: $5 \mathrm{~g}$ peptone $+0.1 \mathrm{~g}$ ironphosphate $+750 \mathrm{ml}$ sterile seawater + $250 \mathrm{ml}$ distilled water $\left(+15 \mathrm{~g} \cdot 1^{-1}\right.$ agar for solid test medium). 
For the antibacterial tests, the standard "paper disc diffusion test" was employed. Extract package was 1000-100 $\mu \mathrm{g} \cdot$ paper disc $^{-1}$ (diameter 6-5 $\mathrm{mm}$ ) for gross and fine fractions, respectively. The mean of two vertical diameters per inhibition zone vas noted after 3 days incubation in the dark at $20^{\circ} \mathrm{C}$.

Antifungal: Four strains of marine yeasts were generously provided by Professor Hoppe (IFM, Kiel, FRG): Debaryomyces rhoederi (DR), D. hansenii (DH), Rhodotorula mucilaginosa (RM) and strain "749". Culture medium $\left(\cdot 1^{-1}\right.$ seawater): $5 \mathrm{~g}$ peptone $+2.4 \mathrm{~g}$ powdered meat extract $+20 \mathrm{~g}$ glucose $+1 \mathrm{~g}$ yeast extract $(+15 \mathrm{~g}$ agar for solid medium). Test methods as described above.

Antialgal: Target organisms were the flagellate Isochrysis galbana (IG), the planktonic diatom Skeletonema costatum (SC) and the benthic diatom Navicula sp. (NI).

They were grown in medium $\mathrm{F} / 2$ at $20^{\circ} \mathrm{C}$ and $1800 \mu \mathrm{W} \cdot \mathrm{cm}^{-2}$ light intensity. Medium $\left(\cdot 1^{-1} \quad 0.2 \mu \mathrm{m}\right.$-filtered seawater $): 75 \mathrm{mg} \quad \mathrm{NaNO}_{3}+5 \mathrm{mg} \quad \mathrm{NaH}_{2} \mathrm{PO}_{4}+$ $15-30 \mathrm{mg} \mathrm{Na} \mathrm{SiO}_{3}+4.36 \mathrm{mg} \mathrm{Na} \mathrm{NaDTA}_{2}+3.15 \mathrm{mg} \mathrm{FeCl}+0.01 \mathrm{mg} \mathrm{CuSO}+$ $0.02 \mathrm{mg} \quad \mathrm{ZnSO}_{4}+0.01 \mathrm{mg} \quad \mathrm{CoCl}_{2}+0.18 \mathrm{mg} \quad \mathrm{MnCl}_{2}+0.006 \mathrm{mg} \quad \mathrm{Na}_{2} \mathrm{MoO}_{4}+$ $0.01 \mathrm{mg}$ vitamin $\mathrm{B} 1+0.5 \mu \mathrm{g}$ vitamin $\mathrm{B} 12+0.5 \mu \mathrm{g}$ biotin.

For the bioactivity screening, we used multiwell disposotrays (Linbro, Flow Laboratories) with $1-\mathrm{ml}$ pits. Test concentrations were 150,100 and $50 \mathrm{ppm}$ for primary, secondary and tertiary fractions, respectively. Extracts were added in an amount of their respective solvent (e.g., hexan, butanol, etc.) that in pilot assay had proven without effect with regard to the target organisms tested (usually $<1 \%$ ). Controls with solvent only and with pure medium were run in parallel. Coll motility (for IG and NI) and cell concentration changes were assessed after $1 \mathrm{wk}$ incubation time.

Antimitotic/antilarval: We have chosen sea urchin eggs as objects for this part of the screening because: (1) This has become a standard technique in the field (e.g., Dinnel et al., 1989); (ii) they are easy to obtain; and (iii) this test yields very diverse information about general bioactivities, such as sperm motility inhibition, fertilization inhibition, antimitotic activity, "mutagenic" activity (abnormal development) and ciliary motility inhibition. At least the last three of these probably affect many marine larvae at the moment of settlement. Larval settlement itself cannot be studied by this test.

Eggs and sperm were obtained by injecting $1 \mathrm{ml} 1 \mathrm{M} \mathrm{KCl}$ solution into the body cavity of freshly collected, mature Paracentrotus lividus Lam., which then released their gametes into clean Petri dishes within 10-15 min. For each sex, gametes of four or five individuals were pooled to minimize individual sensitivities vis-à-vis the test extracts. Eggs were suspended in stirred sterile seawater at a concentration of $\approx 100 \mathrm{eggs} \cdot 50 \mu \mathrm{I}^{-1}$. The pits of disposotrays (see above) were filled with $700 \mu \mathrm{l}$ sterile seawater plius $2-20 \mu \mathrm{i}$ of solvent/extract, solvent alone (Control 1) or sterile seawater (Control 2). Extract concentrations were: 1-2-8-12.5-25-50-100-150 ppm (extract addition as above). Either, eggs $(50 \mu$ l containing $\approx 100$ cells $)$ were added to the pits 15 min after the sperm suspension $(10 \mu \mathrm{l}$ strongly diluted, $->$ extract influence on sperm: motility and fertilization) or zygotes were added only at the moment of fertilization membrane appearance ( $->$ extract infiuence on mitosis, development, ciliary motility, etc.). Development was 
monitored over at least $48 \mathrm{~h}$. Reversibility of antimitotic activities was tested by transferring "blocked" cells to pits with sterile seawater (dilution factor 1000-10000: "washing").

\section{RESULTS}

\section{MECHANICAL DEFENSE}

\section{Migrating mucous surface film?}

The quick-motion picture revealed that the particles did wander but not in any coordinated way. They rather tended to accumulate in the small valleys and grooves of the colony surface. As a probable motor of this "migration", the picture sequence revealed rhythmic contractions of the whole colony every few minutes. The existence of any unidirectionally migrating surface film can with some certainty be excluded (see also pigment inclusion results). The absence of surface cilia on $P$. lacazei colonies, too, speaks against such a defense mechanism.

\section{Continuous mucus secretion?}

The stain particles sunk into the outermost layer of the colony surface were stationary over 3 wk. Surface renewal by intense continuous mucus secretion seems not to be an antifouling adaptation in $P$. lacazei.

\section{Sloughing?}

In situ and in vitro monitoring of numerous colonies revealed that $P$. lacazei does shed a cell-free cuticular pellicle, occasionally. Typically, this sloughing marks the end of a "resistance form" phase (Wahl \& Lafargue, 1990) during which the entire colony is sealed by a thin cuticle. This kind of surface is much more susceptible to fouling than the surface of actively filtrating colonies: numerous bacteria, cyanobacteria, diatoms, protozoans and even macroalgae and metazoans (mostly kamptozoans) may be encountered during this phase. Reactivation of the colony is initiated exteriorly by local rupture of the pellicle followed by a slow peeling-off $(\approx 1 \mathrm{wk})$. Finally, the old "skin" is cast with all its attached epibionts. Stereo-microscope examination of 15-20 colonies every 2 wk during $1 \mathrm{yr}(n=910)$ and in situ monitoring of 15 colonies over up to $4 \mathrm{yr}$ showed that at any given moment an irregularly fluctuating mean of $5-6 \%$ of the colonies were of the "resistance form" type or in the state of sloughing. We estimated that this phase, from the first appearance of ihe sealing pellicle to its final casting, lasts for 1-3 wk. If this last approximation is correct, we may assume that, on average, an individual colony sloughs every $4-15$ months. 


\section{PHYSICAL DEFENSE}

Both the air bubbles and the silicone drops always formed contact angles well below $10^{\circ}$ with the colony surface. Consequently, in a seawater bulk phase these two fluids do not wet the outermost layer of a $\boldsymbol{P}$. lacazei colony. This implies that this ascidian's surface tension is greater than that of seawater $\left(\approx 72 \mathrm{dyn} \cdot \mathrm{cm}^{-1}\right)$ and, consequently, lies well outside the "biocompatible range" $\left(20-30 \mathrm{dyn} \cdot \mathrm{cm}^{-1}\right)$. Thus, a physical antifouling defense may be excluded in the case of P. lacazei.

\section{CHEMICAL DEFENSE}

\section{Surface $p H$ ?}

Contact methods. (i) Indicator paper: The results clearly depend on the force by which the paper was applied to the colony surface. On slight touch the wet paper indicated a pH of 7.5 with, occasionally, minuscule acid spots. When pressed firmly onto the colony surface, the result was a $\mathrm{pH}$ of $1-2$. This extremely acid value probably originated from small lesiors of the surface and subsequent leakage of internal acid fluids.

(ii) Filter paper and indicator fluids: The superficial water film on $P$. lacazei shows slightly acid properties: $\mathrm{pH} 6.3 \pm 0.7$.

Contact-free methods. (i) After having washed slowly over the colonial surface the collected seawater exhibited a $\mathrm{pH}$ of 7.47 as compared with its original $\mathrm{pH}$ of 7.54. At this moment, it may not be decided whether this small change was due to contact with a slightly acid colony surface or to some excretory products of the living colony.

(ii) The different indicator fluids did not change color when coming into contact with the submerged colonies' surface. According to Parry (1984), the colonial surface $\mathrm{pH}$ value should consequently range somewhere between 6.8 and 8 . Concluding, the $\mathrm{pH}$ value at a $\boldsymbol{P}$. lacazei surface seems to be between $6-7$. It is unlikely, that these near-neutral properties should impede fouling. Growth of local marine bacteria, for instance, is not slowed down at $\mathrm{pH}$ values between 5-8 (unpubl. data) and even at smallest distances off the surface any acid exudates should be neutralized immediately by the well-buffered seawater. These findings are in accordance with the statement of Davis \& Wright (1989) that, at least in the case of colonial ascidians, "in the field, acidity is not an effective defense against fouling organisms".

\section{Secondary metabolites?}

The results of the biological screening are summarized in Table I for the two active primary fractions (HEX and BUT) and their constituents. As all fractions tested were mixtures of an unknown number of pure compounds, the activity observed cannot be related to individual compound concentrations and the activity ranging $(0-3)$ given in the table is to be considered as relative. 
TABLF. I

Potential defense adaptations detected in P. lacazei. Relative activities of fractions: 0 , none; 1, weak; 2, moderate; 3, strong; empty fields, no tests run. For every final fraction (secondary for BUT fractions, tertiary for HEX fractions), mean relative activity (MRA, $\bar{x}$ ) was calculated for each fouling group. Grey shadowing, fractions or mechanisms with good activity against a given group of foulers (MRA $\leq 0.5$ ),

\begin{tabular}{|c|c|c|c|c|c|c|c|c|c|}
\hline \multicolumn{4}{|c|}{ Extracts } & \multicolumn{6}{|c|}{ Antibacterial } \\
\hline \multirow{2}{*}{$\begin{array}{l}\text { Chemical } \\
\text { groups }\end{array}$} & \multicolumn{3}{|c|}{ Fractions } & \multicolumn{2}{|c|}{ Gram-positive } & \multicolumn{3}{|c|}{ Gram-negative } & \multirow[t]{2}{*}{$\bar{x}$} \\
\hline & Primary & Secondary & Tertiary & IG3 & CYS & IGI & IG2 & Pseud & \\
\hline \multirow{6}{*}{$\begin{array}{l}\text { Lipids } \\
\text { and } \\
\text { steroids }\end{array}$} & HEX & & & 1 & \multirow{6}{*}{2} & & 0 & 1 & \\
\hline & & $\mathrm{HI}-\mathrm{H} 7$ & & & & 0 & $\mathbf{0}$ & $\mathbf{0}$ & \\
\hline & & H8-H11 & & 2 & & 2 & 1 & 3 & \\
\hline & & $\mathrm{H} 12-\mathrm{H} 13$ & & 1 & & 1 & 1 & 1 & \\
\hline & & H14 & & & & & & 1 & \\
\hline & & $\mathrm{H} 15-\mathrm{H} 19$ & & & & & & 1 & \\
\hline \multirow[t]{2}{*}{ Lipids } & & & H10.1 & 2 & & 2 & 2 & 2 & 2 \\
\hline & & & $\mathrm{H} 10.2$ & 1 & & 1 & 1 & 2 & 1.25 \\
\hline \multirow[t]{6}{*}{ Steroids } & & & H10.3 & 1 & & 0 & 0 & 0 & 0.25 \\
\hline & & & HI0.4 & 1 & 1 & 0 & 0 & 1 & 0.6 \\
\hline & & & HI0.5 & 1 & & 0 & 0 & 2 & 0.6 \\
\hline & & & H10.7 & $\mathbf{0}$ & & 0 & & 1 & 0.33 \\
\hline & & & \multirow[t]{2}{*}{ Mean sum 1} & & & & & & 5.03 \\
\hline & BUT & & & 3 & & 1 & 0 & 2 & \\
\hline Proteins (?) & & B0 & & 3 & 2 & 0 & & 1 & 1.5 \\
\hline \multirow[t]{2}{*}{ Polypeptides } & & B1 & & 0 & 0 & 0 & & & 0 \\
\hline & & B2 & & 0 & 0 & 0 & & 0 & 0 \\
\hline \multirow{9}{*}{$\begin{array}{l}\text { Peptides } \\
\text { or } \\
\text { sugars }\end{array}$} & & B3 & & 0 & 0 & 0 & & 0 & 0 \\
\hline & & B4 & & 0 & 0 & 0 & & 0 & 0 \\
\hline & & B5 & & 0 & 0 & 0 & & 0 & 0 \\
\hline & & B6 & & 0 & 0 & 0 & & & 0 \\
\hline & & B7 & & 0 & 0 & 0 & & & 0 \\
\hline & & B8 & & 0 & 0 & 0 & & & 0 \\
\hline & & B9 & & 0 & 0 & 0 & & & 0 \\
\hline & & Mean sum 2 & & & & & & & 1.5 \\
\hline & & Mean totaì & & & & & & & 6.53 \\
\hline
\end{tabular}

Further defenses

Sloughing

Grazing Hyadesia

Tisbe

Antibacterial. Moderate-to-strong bacteriostatic activity was found against all five strains tested. The antibacterial properties of the primary fractions HEX and BUT seem to be due mainiy to the tertiary fractions $\mathrm{H} 10.1 / \mathrm{H} 10.2$ (lipids) and the secondary fraction B0, respectively. Thus, at least two different antibacterial compounds are found in P. lacazei.

Antifungal. A rather moderate activity against three out of the four yeasts tested was detected in the tertiary fractions $\mathrm{H} 10.3$ and $\mathrm{H} 10.4$ (steroids). 
illustrating that ail tested potential colonizers are inhibited simultaneously by sevc.al fractions and/or mechanisms. Sums of MRAs in each group have served to dress Fig. 2. Cil, "anticiliary"; Diat, "antidiatom"; Fla, "antiflagellate"; Mit, "antimitotic"; Mut, "mutagenic" activity (for further abbreviations, see text). Chemically very similar fractions are pooled.

\begin{tabular}{|c|c|c|c|c|c|c|c|c|c|c|c|c|c|}
\hline \multicolumn{5}{|c|}{ Antifungal } & \multicolumn{4}{|c|}{ Antialgal } & \multicolumn{5}{|c|}{ Antilarval } \\
\hline \multirow[t]{2}{*}{ DR } & \multirow[t]{2}{*}{ DH } & \multirow[t]{2}{*}{ RM } & \multirow[t]{2}{*}{749} & \multirow[t]{2}{*}{$\bar{x}$} & \multirow{2}{*}{$\frac{\mathrm{Fla}}{\mathrm{IG}}$} & \multicolumn{2}{|c|}{ Diat } & \multirow[t]{2}{*}{$\bar{x}$} & \multirow[t]{2}{*}{ Mit } & \multirow[t]{2}{*}{ Cil } & \multirow[t]{2}{*}{ Mut } & \multirow[t]{2}{*}{ Sum } & \multirow[t]{2}{*}{$\bar{x}$} \\
\hline & & & & & & $\mathrm{SC}$ & $\mathrm{NI}$ & & & & & & \\
\hline \multirow[t]{3}{*}{0} & 0 & 0 & 0 & & & & & & 2 & 0 & 0 & & \\
\hline & 1 & & & & & 0 & 0 & & & & & & \\
\hline & 1 & 1 & & & & 1 & 1 & & 1 & & & & \\
\hline \multirow{2}{*}{0} & 0 & 0 & 0 & & & 1 & $\begin{array}{l}2 \\
0\end{array}$ & & $\begin{array}{l}1 \\
2\end{array}$ & & & & \\
\hline & & & & & & 2 & 1 & & 0 & & & & \\
\hline 0 & $\mathbf{0}$ & 0 & 0 & 0 & & & 2 & 2 & 0 & 0 & 0 & 0 & 0 \\
\hline 0 & 0 & 0 & 0 & $\mathbf{0}$ & & & 1 & 1 & 0 & 3 & 0 & 3 & 1 \\
\hline 0 & 0 & 1 & & 0.33 & & & 0 & & 0 & 0 & 0 & 0 & 0 \\
\hline 1 & 1 & 1 & & 1 & & & 0 & & 0 & 0 & 0 & 0 & 0 \\
\hline 0 & 0 & 0 & 0 & 0 & & & 0 & & 0 & 0 & 0 & 0 & 0 \\
\hline \multirow[t]{2}{*}{0} & & 0 & & 0 & & & & & 0 & 0 & 0 & 0 & 0 \\
\hline & & & & 1.33 & & & & 3 & & & & & 1 \\
\hline 0 & 0 & 0 & 0) & & 3 & 2 & 2 & & 2 & 3 & 0 & & \\
\hline 0 & () & 0 & 0 & 0 & 3 & 3 & 2 & 2.7 & 1 & 3 & 0 & 4 & 1.33 \\
\hline 0 & 0 & 0 & 0 & 0 & & & & & 0 & & 0 & 0 & 0 \\
\hline 0 & 0 & 0 & 0 & 0 & & & & & 0 & & 0 & 0 & 0 \\
\hline 0 & 0 & 0 & 0 & 0 & & & & & 0 & & 0 & 0 & 0 \\
\hline 0 & 0 & 0 & 0 & 0 & & & & & 0 & & 0 & 0 & 0 \\
\hline 0 & 0 & 0 & 0 & 0 & 0 & 0) & 0 & 0 & 1 & 1 & 0 & 2 & 0.67 \\
\hline 0 & 0 & 0 & 0 & 0 & () & 1 & i) & 10.33 & 2 & 0 & 0 & 2 & 0.67 \\
\hline 0 & 0 & 0 & 0 & 0 & & & & & 0 & 1 & 0) & 1 & 0.33 \\
\hline 0 & 0 & 0 & 0 & 0 & & & & & 0 & 0 & 2 & 2 & 0.67 \\
\hline \multirow[t]{3}{*}{0} & 0 & 0 & 0 & 0 & & & & & 0 & 0 & 0 & 0 & 0 \\
\hline & & & & 0 & & & & 3.03 & & & & & 3.67 \\
\hline & & & & 1.33 & & & & 6.113 & & & & & 4.67 \\
\hline
\end{tabular}

Antialgal. This part of the screening was started later and not all fractions were tesied. Again, the lipids $\mathrm{H} 10.1 / \mathrm{H} 10.2$ were the most active in the lipophilic group and inhibited growth of the benthic Navicula sp. Among the hydrophilic extracts, only B0 strongly blocked the growth of both flagellates and diatoms. The most potent antialgal activity was detected in the primary fraction BUT (synergistic effects?). Examples for $100 \%$ inhibition concentrations: 5 ppm BUT vs. NI, 7 ppm B0 vs. SC and IG, 10 ppm H10.1 vs. NI, $40 \mathrm{ppm}$ B0 vs. NI. The activity of BUT vs. SC is perfectly reversible: Cells blocked during $92 \mathrm{~h}$ by $150 \mathrm{ppm}$ BUT proliferated normally when transferred to extract- 
free medium. Thus, $P$. lacazei possesses at least two antialgal secondary metabolites: one a lipid, the other probably a protein.
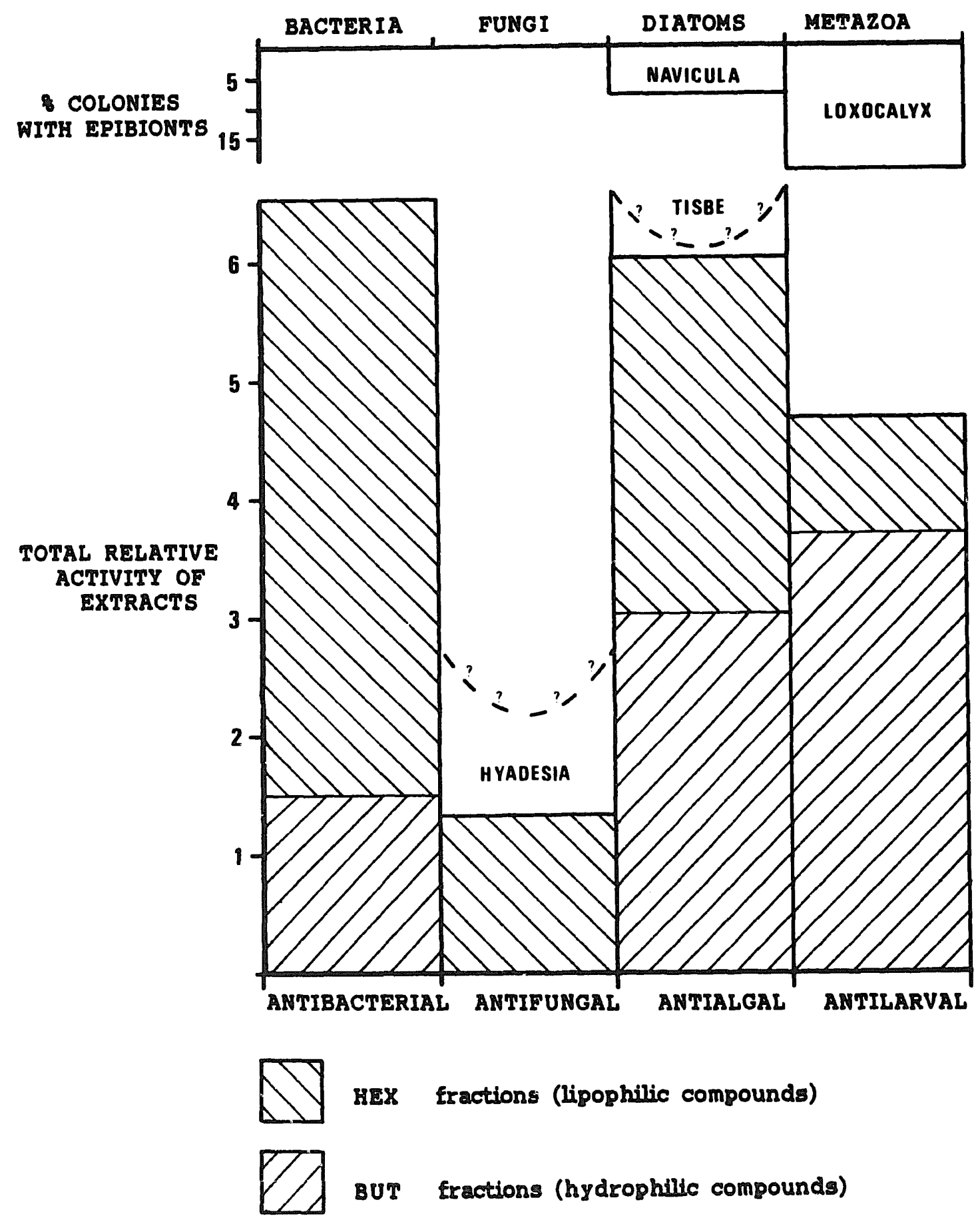

Fig. 2. Relative "antifouling" defense intensity against four groups of potential colonizers examined (sums of MRAs from Table I). Contribution to protective shield by grazing activities of Hyadesia sp. and Tisbe sp. cannot be quantified. In upper part of figure: percentage of fouled colonies. 
Antimitotic/antilarval. The moderate antimitotic activity of the primary fraction HEX could be followed to the secondary fractions $\mathrm{H} 12 / \mathrm{H} 13$ and $\mathrm{H} 14$ but not pursued further for lack of material. $\mathrm{H} 10$ blocked the development at the morula stage while the first cleavages seemed normal. In the tertiary fractions derived from $\mathrm{H} 10$, the original antimitotic activity observed in HEX was lost but H10.2 did block reversibly the ciliary activity of developing larvae at $100 \mathrm{ppm}$ and slowed it down significantly at $12.5 \mathrm{ppm}$. At both concentrations, the larvae died when reaching the morula stage whereas a transfer to extract-free medium after $1 \mathrm{~h}$ exposure to $100 \mathrm{ppm} \mathrm{H10.2} \mathrm{permitted} \mathrm{normal}$ development.

Development of sea urchin eggs was impeded mainly by the BUT group. The primary fraction (BUT) inhibited mitosis and reversibly blocked ciliary activity. In the secondary fractions, the antimitotic activity could be detected in B6 (at $8 \mathrm{ppm}$ ) while BC strongly (8 ppm) and reversibly ( $1 \mathrm{hi}$ exposure) inhibited ciliary activity and fertilization. B5 and B7 exhibited the same properties as B0 but at higher concentrations (35-70 ppm) and in this case irreversibly. B8 had no apparent influence on fertilization, mitosis or ciliary beat but led to the appearance of highly motile, yet extremely malformed ("monstrous") larvae at $35 \mathrm{ppm}$.

Further activities. (i) In Ca-free seawater, BUT inhibits irreversibly the hormoneinduced cleavage of unfertilized eggs of the sea star Marthasterias glacialis L. at $1 \mathrm{ppm}$ and in the absence of $\mathrm{Ca}$ and $\mathrm{Mg}$ at $0.1 \mathrm{ppm}$. When cell division is unblocked by washing zygotes that had been exposed to $25 \mathrm{ppm}$ BUT for several hours, immediately the same cleavage stage as in the controls appears (e.g., 32-cell stage). This seems to suggest that under the influence of BUT the chromatine cycle had evolved normally while the cytoplasm cleavage was inhibited. Finally, BUT exhibits moderate antiprotease activities against pepsine and trypsine. The antitrypsine activity is concentrated essentially in the secondary fractions B0 and B1.

(ii) B0 (8 ppm) inhibits the appearance of a fertilization membrane even if this is stimulated by adding $\mathrm{Ca}$ ionophores.

Consequently, P. lacazei possesses at least one anticiliary lipid and several antimitotic, anticiliary and/or "mutagenic" compounds in the BUT group. A combined action of these secondary metabolites, if bound to or released at the colony surface, should quite efficiently inhibit development and survival of settling larvae. Regrettably, we did not have the means to assess metabolite concentration at the colony surface. Thus, any release of the potential antifoulants into the surrounding seawater must stay hypothetical for the time being.

\section{F.XTRINSIC DEFENSE}

On the surface of the colonies examined $(n=910)$ two vagile metazoans were found regularly: the harpacticoid Tisbe sp. and the acarid Hyadesia sp. Stomach contents analysis of the copepod showed that it mainly contained benthic diatoms, especially 
Navicula, while the mite is known to be fungivorous (F. Binche, Laboratoire Arago, pers.comm.). It is quite possible that the grazing activity of $H y a d e s i a$ and Tisbe supports the ascidian's antifungal and antialgal defenses.

\section{CONCLUSION}

In a former paper (Wahi \& Lafargue, 1990), an antifouling potential index was proposed:

$$
A F P=(1-E / C P) \times A /(F P+A),
$$

where $E=$ number of regular epibiont species on a given basibiont (presence $\geq 10 \%$ ), $C P=$ local colonizer pool, $A(\max 1 \mathrm{yr})=$ exposure time or longevity of basibiont and $F P=$ fouling period.

In the case of $P$. lacazei, $A$ was attributed the maximum value $1 \mathrm{yr}$ (mean colony longevity $\approx 18$ months), $E$ was 1 (Loxocaly $x$ sp.), $F P$ approximated $3 \mathrm{wk}$ ( $=0.06 \mathrm{yr}$ from immersion of test plates to arrival of metazoan larvae) and $C P$ estimates range from 70 (metazoan epibionts on the cohabitat ascidian Microcosmus sabatieri; Monniot, 1961) to $>2000$ (for literature data, see Wahl, 1987). Thus, the most cautious estimate of $P$. lacazei-AFP is:

$$
(1-1 / 70) \times 1 /(0.06+1)=0.93,
$$

forecasting potent antifouling defense adaptations in this ascidian according to the definitions given in Wahl \& Lafargue (op.cit.).

The results of this study show that in the present case the pro gnostic proved valid. Beside the action of associated epibiont grazers and the ability to slough, $P$. lacazei possesses several secondary metabolites that together efficiently inhibit growth and/or survival of all potential colonizers tested: bacteria, fungi, unicellular algae and larvae. Furthermore, the detected activities and mechanisms overlap in two ways (see Table I):

(i) Single fractions or mechanisms may inhibit more than one fouling group but not always with the same efficiency, for example:

H10.2: (strongly) anticiliary + (moderately) antibacterial + (weakly) antialgal.

B0: (strongly) anticiliary + (moderately) antialgal + (weakly) antibacterial.

A sloughing event, naturally, removes all epibionts.

(ii) Single fouling groups may be inhibited by more than one fraction (or mechanism), for example:

Bacteria $\quad: \mathrm{H} 10.1+\mathrm{H} 10.2+\mathrm{H} 10.4+\mathrm{B} 0$.

Fungi $\quad: \mathrm{H} 10.4+$ grazing by Hyadesia.

Diatoms (NI) : $\mathrm{H} 10.1+\mathrm{H} 10.2+\mathrm{B} 0+$ grazing by Tisbe.

Larvae $\quad: \mathrm{H} 10.2+\mathrm{B} 0+\mathrm{B} 5+\mathrm{B} 6+\mathrm{B} 7+\mathrm{B} 8$.

The occasional sloughing of the colonies every several months certainly accounts for a sporadical cleaning of the surface. While its cycle (4-15 months estimated) seems too 
long to impede fast colonization by bacteria and diatoms, this mechanism undoubtedly removes periodically the only epibiont which apparently is quite insensitive to secondary metabolites and grazing: Loxocalyx. We have observed repeatedly that the kamptozoan population was particularly dense on colonies just before or during the "resistance form" phase. Whether this was due to reduced ascidian defenses during this period or, on the contrary, whether this phase and the subsequent sloughing were induced by the dense kamptozoan cover (up to 1000 ind $\cdot \mathrm{cm}^{-1}$ ) cannot be decided yet.

Concluding, we could identify overlapping mechanical, chemical and extrinsic mechanisms that might constitute the protective antifouling shield which, in turn, would explain the near-total absence of epibionts on $P$. lacazei in a high fouling pressure environment.

The amazing fact that $P$. lacazei disposes of several independent, (probably) fouling inhibiting mechanisms with respect to each single fouling group could constitute a rather efficient block against the start of coevolutive adaptation by potential colonizers. Apparently, up to now only Loxocalyx sp. has been successful in this regard.

Whether the bioactive secondary metabolites and the sloughing really and/or exclusively serve an antifouling purpose has to remain a presumption. Further data on the localization of the compounds within the colony (concentration in the coloniai surface?) and on the influence of changing colonizing pressure on defense intensity (inducibility?), for instance, should bring us closer to a definitive answer.

\section{ACKNOWLEDGEMENTS}

We are grateful to André Picard, Laboratoire Arago, for valuable help and advice with the biochemical test of extracts vs. development of $M$. glacialis eggs.

\section{REFERENCES}

Davis, A.R. \& A.E. Wright, 1989. Interspecific diffei ences in fouling of two congeneric ascidians (Eudistoma olivaceur: and $E$. capsulatum): is surface acıdity an effective defense? Mur. Biol., Vol. 102, pp. $491-497$.

Dinnel, P.A., J.M. Link, Q.J. Stober, M.W. Letourneau \& W.E. Roberts, 1989: Comparative sensitivity of sea urchin sperm bioassay to metals and pesticides. Arch. Environ. Contam. Toxicol., Vol. 18, pp. 748. 55 .

Monniot, ., 1961. Un conne. Université de Paris, 211 pp.

Neumann, A.W. \& R.J. Good, 1979. Techniques of measuring contact angles. Surf. Colloid Sci., Vol. 11. pp. 31-9i

Parry, D. L., 1s84. Chemica: properties of the test of ascidians in relation to predation. Mar.Ecol.Progr.Ser., Vol. 17 , pp. $279-282$.

Stoecker, D., 1978. Resistance of a tunicate to fnuling. Biol. Bull. (Woods Hole. Mass. ), Vol. 155, pp. 615-626. Stoecker, D., 1980. Chemical defences of ascidians against predators. Ecolog1, Vol. 61, pp. 1327-1335.

Wahl, M., 1987. Epibiosis und Antifouling im Meer. Ph.D. thesis, Universität Kiel, FRG, 140 pp.

Wahl, M., 1989. Marine epibiosis. I. Fouling and antifouling: some basic aspects. Mar. Ecol. Progr. Ser., Vol. 58, pp. 175-189.

Wahl, M. \& F. Lafargue, 1990. A Trine epibiosis. II. Reduced fouling on Folysyncraton lacazei (Didemnidae, Tunicata) and proposal of a antifouling potential index. Oecologia (Berlin), Vol. 82, pp. 275-282. 